\title{
Improvement of Mechanical Properties of 7475 Based Aluminum Alloy Sheets by Controlled Warm Rolling
}

\author{
Hiroki Tanaka, Hiroki Esaki, Kenji Yamada, Kazuhisa Shibue and Hideo Yoshida \\ Research and Development Center, Sumitomo Light Metal Ind. LTD., Nagoya 455-8670, Japan
}

An attempt was made to refine the grain structure of $200 \mathrm{~mm}$ wide sheets of AA7475 based aluminum alloys containing zirconium by employing a new warm rolling method under the control of both roll temperature and material temperature. The warm rolled sheets as solution heat treated had subgrain structures through the thickness with a high proportion of low angle boundary less than $15^{\circ}$. The average subgrain diameter was approximately $3 \mu \mathrm{m}$. The strength of the warm rolled sheets in T6 condition was about $10 \%$ higher than that of conventional AA7475 alloy sheets produced by cold rolling. As the most remarkable point in the warm rolled sheets, the high Lankford $(r)$ value of 3.5 was measured in the orientation of $45^{\circ}$ to rolling direction, with the average r-value of 2.2. The high $r$-value would be derived from well developed $\beta$ fiber textures, especially with the strong $\{011\}\langle 211\rangle$ Brass component. The warm rolled sheets also had high resistance to SCC. From Kikuchi lines analysis and TEM images, it was found that PFZs were hardly formed along the low angle boundaries of the warm rolled sheets in T6 condition. This would be a factor to lead to the improvement of resistance to SCC because of reducing the difference in electrochemical property between the grain boundary area and the grain interior.

(Received June 25, 2003; Accepted October 30, 2003)

Keywords: warm rolling, aluminum-zinc-magnesium-copper, super metal, stress corrosion cracking (SCC), Lankford value

\section{Introduction}

In order to use wrought aluminum alloys for structural components, it is important to improve their mechanical properties on resistance to corrosion and formability as well as strength for high reliability, good design and weight saving. It is well known in low-carbon steels that yield stress has a relationship with grain size, ${ }^{1,2)}$ and the relationship can be applied to aluminum alloy sheets. Due to the fact, the grain refinement of aluminum alloy sheets is one useful method to achieve high strength. On the other hand, it was reported that the grain refinement of AA7075 alloy sheets has a disadvantage on resistance to stress corrosion cracking (SCC). ${ }^{3)} \mathrm{It}$ would be difficult to establish a process that can achieve the improvement of all properties mentioned above at the same time. Therefore, in practical use, some of the mechanical properties should be improved moderately according to circumstances where materials are used.

In prior studies, ${ }^{4,5,7)}$ it was revealed that control of roll temperature and addition of zirconium are important to refine microstructures of AA7475 based aluminum alloy sheets after a solution heat treatment. In the studies, a new type of roll embedded cylindrical heaters was used and prevented reduction of sample temperature in the warm rolling process. Hereafter, this type of rolling is called controlled warm rolling. By making use of the controlled warm rolling, the average subgrain diameter less than $3 \mu \mathrm{m}$ can maintain after a solution heat treatment in AA7475 based aluminum alloy sheets containing zirconium. These warm rolled sheets had no large recrystallized grain and a very high proportion of low angle boundary less than $15^{\circ}$. Consequently, the microstructures of the warm rolled sheets can be called subgrain structure. It was also known that such subgrain structures can't be formed in AA7475 aluminum alloy sheets by the controlled warm rolling ${ }^{4}$ nor in the same kind of aluminum alloys containing zirconium by a conventional cold rolling process. ${ }^{6)}$

The objective of the present work was to clarify mechan- ical properties of the warm rolled sheets of AA7475 based aluminum alloys containing zirconium with the subgrain structure comparing with conventional AA7475 aluminum alloy sheets produced by cold rolling.

\section{Experimental Procedures}

Table 1 shows the chemical compositions of Al-Zn-Mg-Cu alloys used in this experiment. The mark $\mathrm{M}$ means an AA7475 based aluminum alloy containing zirconium instead of chromium. The mark $\mathrm{S}$ means a conventional AA7475 aluminum alloy. The alloy $\mathrm{M}$ was cast into slabs as shown in Table 2 by a standard semi-continuous direct chill technique. The slab was homogenized at $470^{\circ} \mathrm{C}$ for $10 \mathrm{~h}$ followed by pre-heating at $350^{\circ} \mathrm{C}$ for $10 \mathrm{~h}$ before forging at $350^{\circ} \mathrm{C}$. In the forging stage, a sample was compressed from $100 \mathrm{~mm}$ high to

Table 1 Chemical composition of specimens (mass\%).

\begin{tabular}{ccccccccccc}
\hline Alloy & $\mathrm{Si}$ & $\mathrm{Fe}$ & $\mathrm{Cu}$ & $\mathrm{Mn}$ & $\mathrm{Mg}$ & $\mathrm{Cr}$ & $\mathrm{Zn}$ & $\mathrm{Ti}$ & $\mathrm{Zr}$ & $\mathrm{Al}$ \\
\hline $\mathrm{M}$ & 0.02 & 0.03 & 1.64 & $<0.01$ & 2.40 & $<0.01$ & 5.55 & 0.03 & 0.17 & Bal. \\
\hline $\mathrm{S}$ & 0.04 & 0.03 & 1.51 & $<0.01$ & 2.26 & 0.21 & 5.38 & 0.04 & $<0.01$ & Bal.
\end{tabular}

Table 2 Experimental procedure on Alloy M.

\begin{tabular}{cc}
\hline Stage & Condition \\
\hline Casting & $\begin{array}{c}\text { Semicontinuous direct chill techniques into slab } \\
100 \mathrm{~mm} \times 175 \mathrm{~mm} \times 175 \mathrm{~mm}\end{array}$ \\
\hline Homogenization & $470^{\circ} \mathrm{C}-10 \mathrm{~h}$ \\
\hline Pre-heating & $350^{\circ} \mathrm{C}-10 \mathrm{~h}$ \\
\hline Forging & $350^{\circ} \mathrm{C}, 100 \mathrm{~mm} \rightarrow 30 \mathrm{~mm}$ \\
\hline Machining & $30 \mathrm{~mm} \times 200 \mathrm{~mm} \times 100 \mathrm{~mm}$ \\
\hline Warm rolling & $350^{\circ} \mathrm{C}, 27 \mathrm{passes}$ \\
\hline Annealing & $350^{\circ} \mathrm{C}-30 \mathrm{~min}$ \\
\hline Solution heat treatment & $480^{\circ} \mathrm{C}-5 \mathrm{~min} \mathrm{~W} . \mathrm{Q}$. \\
\hline Artificial aging & $120^{\circ} \mathrm{C}-24 \mathrm{~h}$ \\
\hline
\end{tabular}


$30 \mathrm{~mm}$ high. The forged sample was machined with dimensions of $30 \mathrm{~mm}$ high, $200 \mathrm{~mm}$ wide and $100 \mathrm{~mm}$ long. This block was rolled at $350^{\circ} \mathrm{C}$ with re-heating at $350^{\circ} \mathrm{C}$ for $1800 \mathrm{~s}$ after every two passes up to $4 \mathrm{~mm}$ thick followed by every pass up to $1 \mathrm{~mm}$ thick. 27 rolling passes (one pass reduction; $2 \mathrm{~mm}$ per pass up to $10 \mathrm{~mm}$ thick, $1 \mathrm{~mm}$ per pass up to $9 \mathrm{~mm}$ thick and $0.5 \mathrm{~mm}$ per pass up to $1 \mathrm{~mm}$ thick) were carried out in total and the sheets were finally prepared with dimensions of $1 \mathrm{~mm}$ thick and $200 \mathrm{~mm}$ wide.

The surface temperatures of the rolls were controlled at approximately $100^{\circ} \mathrm{C}$ by cylindrical heaters. The roll was $160 \mathrm{~mm}$ in diameter and rotated 120 revolutions a minute. Commercial machine oil was used in the warm rolling process.

Regarding the alloy $\mathrm{S}$, hot rolled plates used in this study were produced commercially by making use of a large slab by semi-continuous direct chill technique. The plates were heated as an intermediate annealing at $480^{\circ} \mathrm{C}$ for $2 \mathrm{~h}$ followed by furnace cooling, then rolled to $1 \mathrm{~mm}$ thick at an ambient temperature.

Solution heat treatment was carried out at $480^{\circ} \mathrm{C}$ for $300 \mathrm{~s}$ followed by quenching into water immediately (T4 condition). After the quenching, artificial aging was carried out at $120^{\circ} \mathrm{C}$ for $24 \mathrm{~h}$ (T6 condition).

Microstructure was observed using an optical microscope and a transmission electron microscope (TEM). Misorientation angles between grains were measured using electron backscattered diffraction (EBSD) equipment with a scanning electron microscope (SEM). X-ray diffraction method was used to describe incomplete pole figures, and orientation distribution functions (ODFs) were calculated from three incomplete pole figures of $\{111\},\{110\}$ and $\{100\}$ by the harmonic method. ${ }^{8)}$ The ODFs were displayed using Bunge's system. ${ }^{8)}$ The mechanical properties of the samples in T6 condition were investigated. Tensile test specimens were got from the orientations of $0^{\circ}, 45^{\circ}$ and $90^{\circ}$ to the rolling direction. The specimens for limiting draw ratio (LDR) measurement were annealed at $360^{\circ} \mathrm{C}$ for $2 \mathrm{~h}$ followed by furnace cooling ${ }^{9)}$ (O temper) to ensure deep drawing property. LDR measurement was carried out with a punch of $33 \mathrm{~mm}$ in diameter in hold-down force of 3,900 N. The test method of resistance to stress corrosion cracking (SCC) in T6 condition was based on Japanese industrial standard, JIS H8711. The specimens for this test were got from the orientation of $90^{\circ}$ to the rolling direction, and were immersed in a solution containing 3.5 mass $\%$ sodium chloride for 10 minutes followed by drying at $25^{\circ} \mathrm{C}$ for 50 minutes with addition of stress controlled at $85 \%$ of yield strength. The above cycle was repeated until the specimens were failed. The resistance to SCC was estimated by a time to failure of the specimens. Exfoliation corrosion susceptibility was examined based on ASTM G34, EXCO test. Specimens in T6 condition were immersed for $9 \mathrm{~h}$ in a solution containing $4 \mathrm{M}$ sodium chloride, $0.5 \mathrm{M}$ potassium nitrate, and $0.1 \mathrm{M}$ nitric acid at $25^{\circ} \mathrm{C}$. The susceptibility to exfoliation was determined by visual examination according to the standard photographs in the designation. Specimens of fatigue test were got from parallel to the rolling direction and machined with dimensions shown in Fig. 1. In this work, the axial loading fatigue test was conducted at a room temperature with the stress ratio of 0.1 and the cyclic of $30 \mathrm{~Hz}$.

\section{Results}

\subsection{Microstructure in $\mathbf{T} \mathbf{4}$ condition}

Figure 2 shows optical micrographs in L-ST section at the center and $30 \mathrm{~mm}$ position from the edge of the warm rolled sheet in T4 condition. Fibrous structure is maintained and no recrystallized grain is observed. Figure 3 compares microstructures between the warm rolled and cold rolled sheets in T4 condition. In optical micrographs, it is found the cold rolled sheet $(\mathrm{CR})$ consists of equiaxed grains about $20 \mu \mathrm{m}$ in

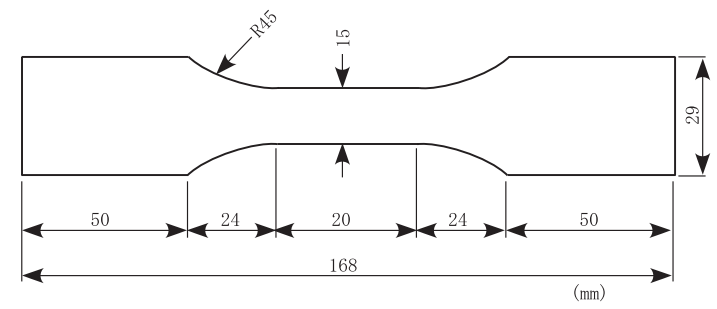

Fig. 1 Shape and dimensions of fatigue specimen.

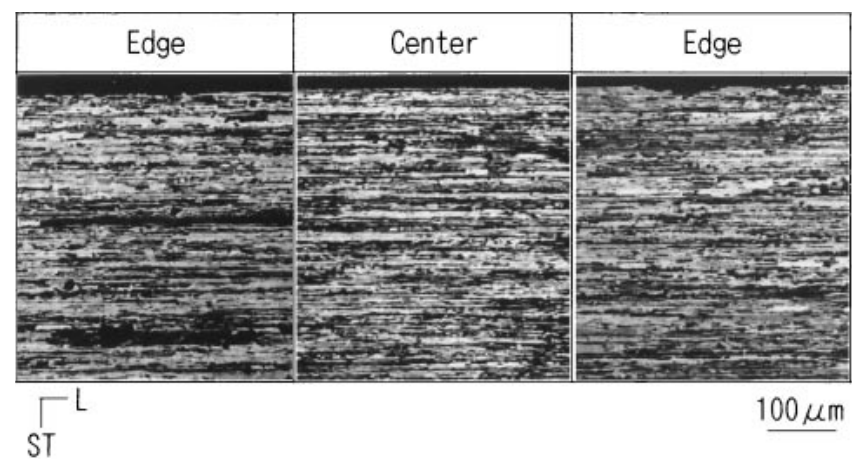

Fig. 2 Optical micrographs of warm rolled sheet in T4 condition.

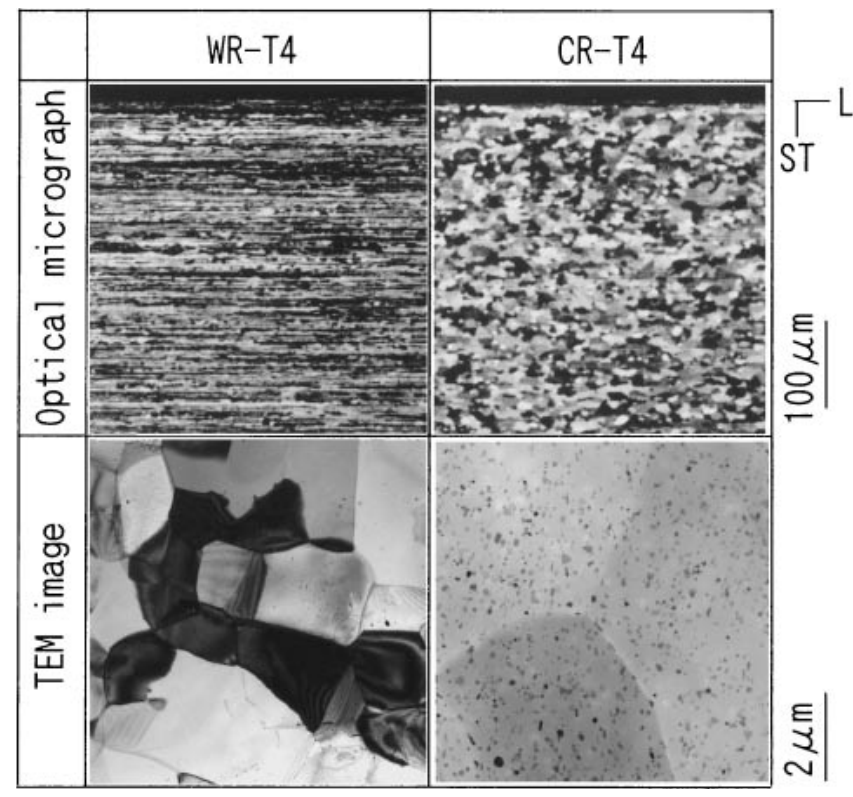

Fig. 3 Optical and TEM micrographs in T4 condition. WR: warm rolled sheet (Alloy M), CR: cold rolled sheet (Alloy S). 


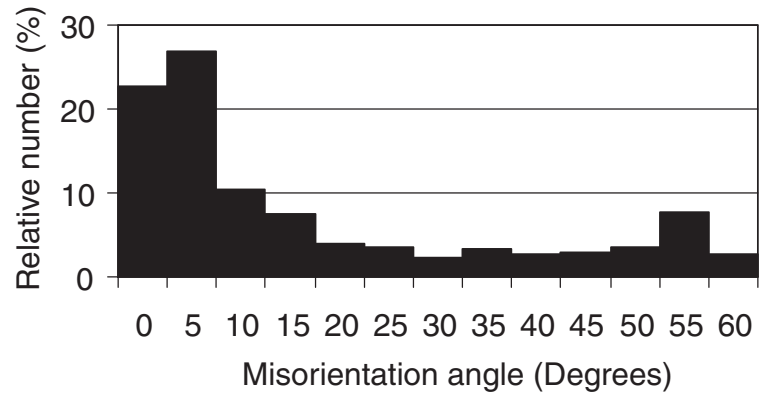

(a) warm rolled sheet

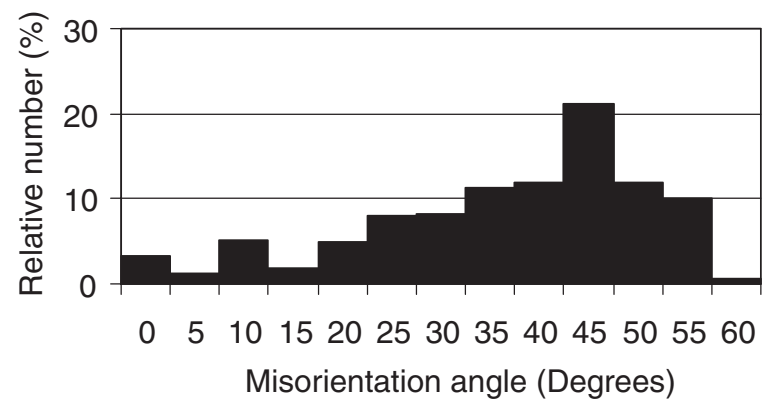

(b) cold rolled sheet

Fig. 4 Misorientation angle histograms of (a) warm rolled sheet and (b) cold rolled sheet in $\mathrm{T} 4$ condition.

diameter, whereas the warm rolled sheet (WR) maintains fibrous structure as mentioned above. In TEM, it is revealed the warm rolled sheet consists of fine grains whose average diameter is approximately $3 \mu \mathrm{m}$. According to the previous work, ${ }^{4)}$ fine particles are judged as $\mathrm{Al}_{3} \mathrm{Zr}$ in alloy $\mathrm{M}$ (warm rolled sheet) and $\mathrm{Al}_{18} \mathrm{Cr}_{2} \mathrm{Mg}_{3}$ in alloy $\mathrm{S}$ (cold rolled sheet).

\subsection{Distribution of misorientation angle in $\mathbf{T} 4$ condition}

Figure 4 shows misorientation angle histograms taken from SEM-EBSD measurements. The measured area in this work was $100 \mu \mathrm{m} \times 200 \mu \mathrm{m}$. The warm rolled sheets have a high proportion of low angle boundary less than $15^{\circ}$, whereas the cold rolled sheet has a high proportion of high angle boundary. According to this measurement, it is clear the warm rolled sheet consists of subgrain structure.

\subsection{Tensile properties and LDR measurements}

Table 3 summarizes tensile test results in T6 condition. The tensile strength of the warm rolled sheet is about $10 \%$ higher in orientations of $0^{\circ}$ and $90^{\circ}$ to rolling direction than that of the cold rolled sheet, and the tensile strength in $45^{\circ}$

Table 3 Mechanical properties of warm rolled sheet and cold rolled sheet in $\mathrm{T} 6$ condition.

\begin{tabular}{rcccc}
\hline Condition & Angle to RD & $\begin{array}{c}\text { Tensile strength } \\
(\mathrm{MPa})\end{array}$ & $\begin{array}{c}\text { Yield strength } \\
(\mathrm{MPa})\end{array}$ & $\begin{array}{c}\text { Elongation } \\
(\%)\end{array}$ \\
\hline Alloy M & $0^{\circ}$ & 592 & 496 & 13 \\
\cline { 2 - 5 } WR-T6 & $45^{\circ}$ & 522 & 461 & 19 \\
\cline { 2 - 5 } & $90^{\circ}$ & 601 & 455 & 13 \\
\hline Alloy S & $0^{\circ}$ & 522 & 461 & 16 \\
\cline { 2 - 5 } CR-T6 & $45^{\circ}$ & 521 & 457 & 17 \\
\cline { 2 - 5 } & $90^{\circ}$ & 526 & 468 & 16 \\
\hline
\end{tabular}

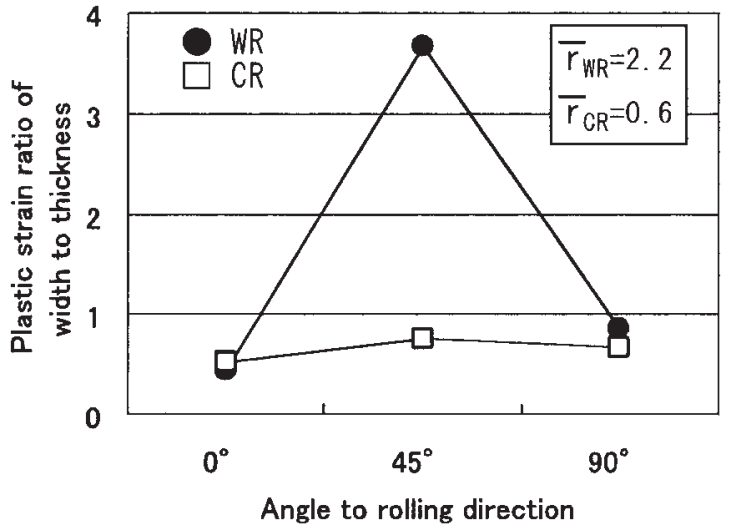

Fig. 5 Plastic strain ratio of width to thickness in T6 condition. WR: warm rolled sheet, CR: cold rolled sheet, $\overline{\mathrm{r}}$ : average r-value.

direction is almost same level in the both sheets. The warm rolled sheet has an anisotropy on ductility, whereas the cold rolled sheet tends to be isotropic on it as well as tensile and yield strengths.

Figure 5 shows the plastic strain ratio of width to thickness (Lankford value: r-value) measured at $10 \%$ elongation. It is remarkable point that the warm rolled sheet has a quite high value over 3.5 in the orientation of $45^{\circ}$ to the rolling direction. The warm rolled sheet also shows anisotropy on $\mathrm{r}-$ value. The average $\mathrm{r}$-value of the warm rolled sheet is 2.2 , meanwhile that of the cold rolled sheet is 0.6.

The results of LDR measurements are shown in Table 4. The warm rolled sheet tends to have a higher value than the cold rolled sheet, and it is found that the LDR values have correlation with the average r-values shown in Fig. 5.

\subsection{Corrosion resistance}

Figure 6 shows the life of SCC in T6 condition. The warm rolled sheets have better resistance to SCC than the cold rolled sheets. Figure 7 shows the appearances and photo-

Table 4 Limiting drawing ratio of warm rolled sheet (WR) and cold rolled sheet $(\mathrm{CR})$.

\begin{tabular}{ccc}
\hline & WR & CR \\
\hline LDR & 2.06 & 2.00 \\
\hline
\end{tabular}

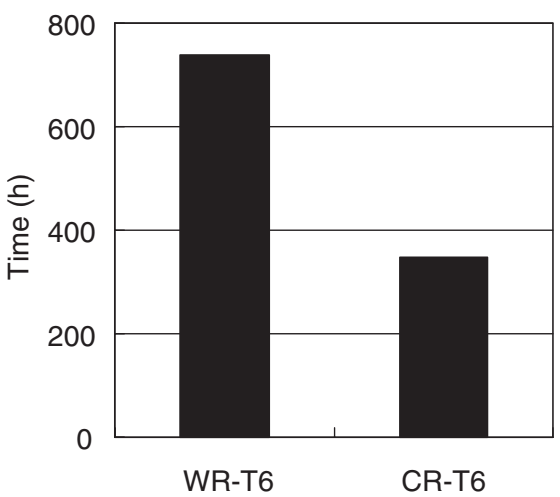

Fig. 6 Life of SCC in T6 condition. WR: warm rolled sheet, CR: cold rolled sheet. 


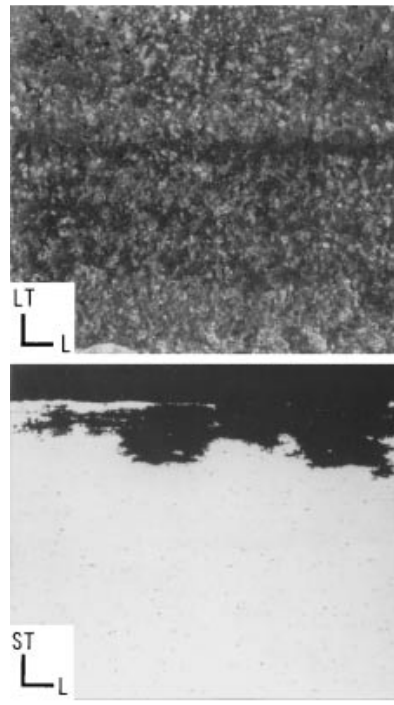

WR (Exfoliation rating EA)

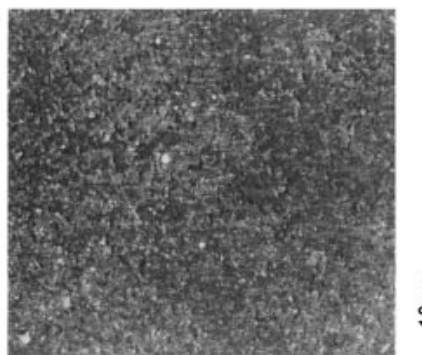

통

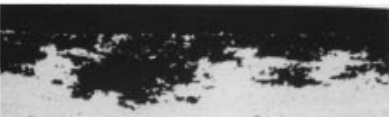

통

CR (Exfoliation rating EA)
Fig. 7 Appearance and photomicrographs showing cross sections of warm rolled sheet (WR) and cold rolled sheet (CR) exposed to the standard EXCO solution for $9 \mathrm{~h}$.

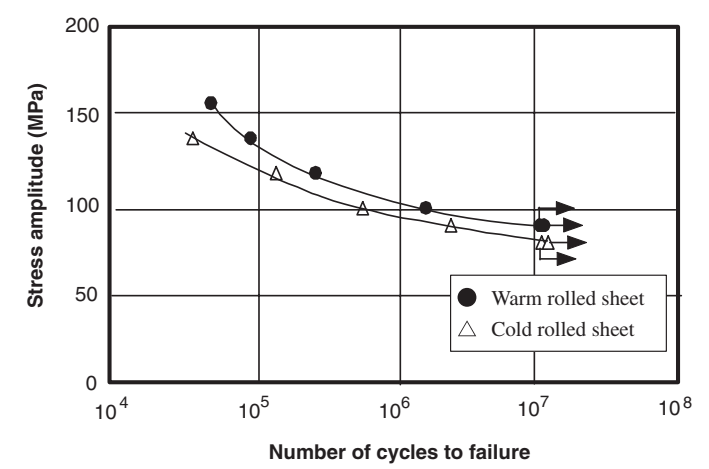

Fig. 8 Stress-number of cycle curves for the specimens in T6 condition.

micrographs of the L-ST section after EXCO test. The both sheets have the same classification and are estimated of EA.

\subsection{Fatigue strength}

Figure 8 gives S-N curves of the samples in T6 condition. The fatigue strength of the warm rolled sheets is about $10 \%$ higher than that of the cold rolled sheets. It is well known that fatigue strength increases with increasing tensile strength. ${ }^{10)}$ Furthermore, the effect of the fibrous structure in the warm rolled sheets on the fatigue strength should be examined in future.

\section{Discussions}

One of remarkable properties on the warm rolled sheets is high r-value shown in Fig. 5. According to the previous work ${ }^{11)}$ based on Taylor theory, ${ }^{12)}$ it was predicted that the rvalue of $45^{\circ}$ orientation would be increased by a $\{011\}\langle 211\rangle$ Brass component. Figure 9 shows the ODFs at the surface layer and center layer of the samples used in this work. The $\{011\}\langle 211\rangle$ Brass component is formed strongly through the thickness of the warm rolled sheet. Regarding to the center layer of the warm rolled sheet, other $\varphi 2$ sections are shown in

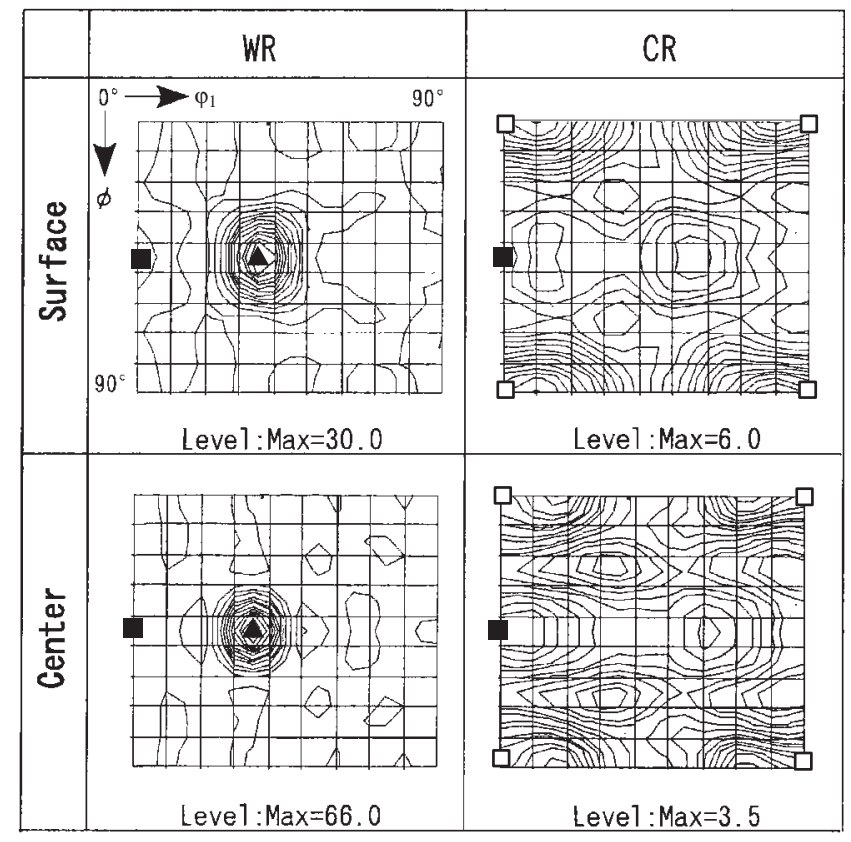

$\mathbf{\Delta}: \operatorname{Brass}\{011\}<211>\square:$ Goss $\{011\}<100>\square:$ Cube $\{001\}<100>$

Fig. 9 ODFs of warm rolled sheet (WR) and cold rolled sheet (CR) in T4 condition. $\varphi_{2}=0^{\circ}$.

Fig. 10. Another orientation near a $\{123\}\langle 634\rangle \mathrm{S}$ component is perceived but its orientation density is lower than the Brass component. It is well known that $\beta$-fiber orientations involve Brass, S and C components. However, a $\{112\}\langle 111\rangle \mathrm{C}$ component was not perceived through the thickness of the warm rolled sheet. According to the above texture analysis, the high $r$-value of the orientation of $45^{\circ}$ in the warm rolled sheet will be derived from the high orientation density of the Brass component. The present results are in agreement with the previous work ${ }^{11)}$ mentioned above. Regarding to the cold rolled sheets, as shown in Fig. 9, ND- and RD-rotated Cube components as well as a $\{011\}\langle 100\rangle$ Goss component are perceived. Their orientation densities are much lower than the Brass component in the warm rolled sheets. Besides of these quite well defined recrystallization texture components, the ODFs comprise the random component. Accordingly, the very weak recrystallization textures with the random component will lead to isotropic tensile properties of the cold rolled sheets. The cold rolled sheets consisted of $\beta$-fiber components in as rolled condition, but the orientation density of the Brass component before solution heat treatment was much lower than that of the warm rolled sheets. ${ }^{5)}$ It would be thought that the strong Brass component in the warm rolled sheets is due to the formation of fine subgrain structure that is quite stable thermally.

In the present work, specimens in O-temper were used for LDR measurements. This O-temper treatment was carried out at $360^{\circ} \mathrm{C}$ after the solution heat treatment at $480^{\circ} \mathrm{C}$, so that it was confirmed the textures of specimens didn't change by the O-temper treatment. Based on this confirmation, it would be found that the average $r$-values have correlation with the LDR values. It would be another subject that precipitation condition may affect drawing properties, but this consideration is beyond the scope of the present work. 


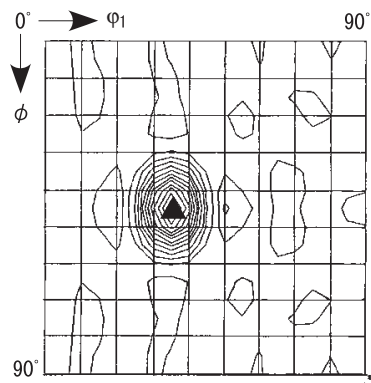

(a) $\varphi_{2}=0^{\circ}: \operatorname{Max}=66.0$ $90^{\circ}$

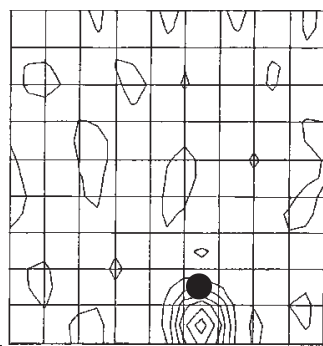

(b) $\varphi_{2}=35^{\circ}: \operatorname{Max}=20.0$

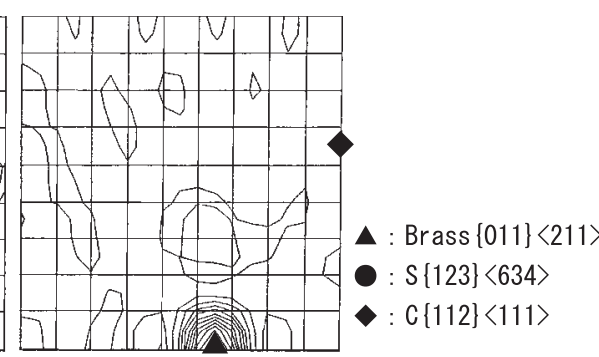

(c) $\varphi_{2}=45^{\circ}: \operatorname{Max}=66.0$

Fig. 10 ODFs of the warm rolled sheet at the center layer in T4 condition.
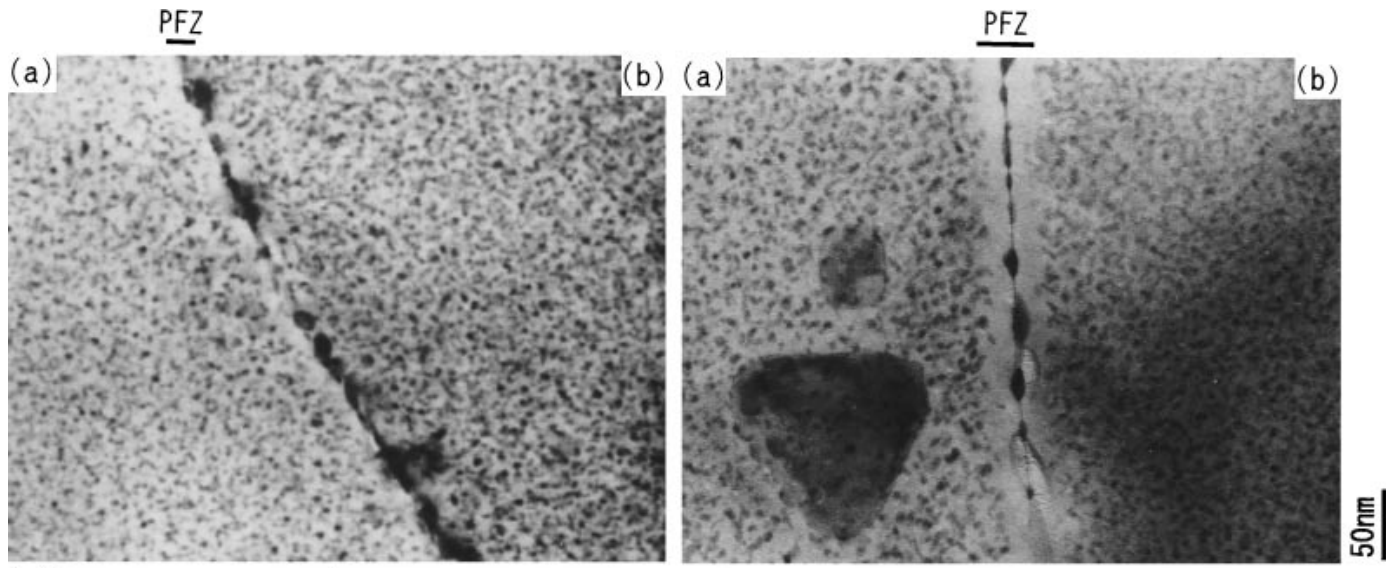
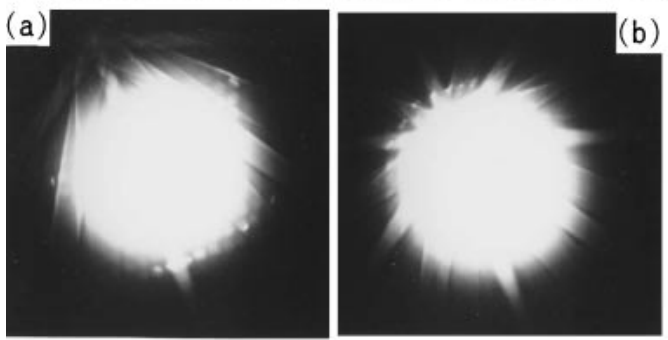

WR (Misorientation angle: $5^{\circ}$ )
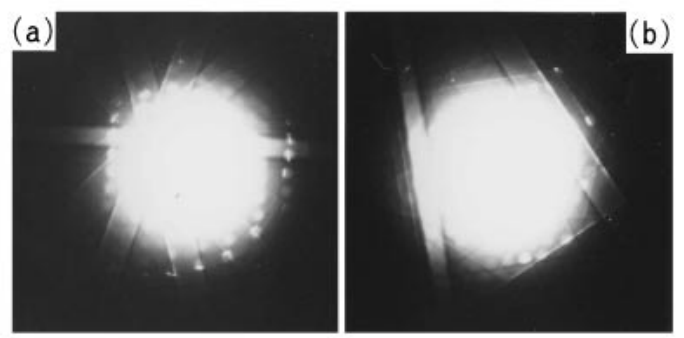

Fig. 11 TEM images and Kikuchi patterns in T6 condition. WR: warm rolled sheet, CR: cold rolled sheet.

In the previous work, $\left.{ }^{6}\right)$ influence of alloy elements in AA7075 was investigated. It was found in the work that addition of zirconium brought about reduction of SCC life in T6 condition. The reason why the warm rolled sheets containing zirconium have good resistance to SCC may be derived from its microstructure. In the previous study on AA6061 alloy extrusions, ${ }^{13)}$ it was suggested the formation of a precipitate free zone (PFZ) is restrained at a low angle boundary, which leads to high resistance to intergranular corrosion. Figure 11 shows TEM images of the samples in T6 condition and Kikuchi patterns derived from two grains facing each other across a grain boundary. From Kikuchi pattern analysis, it was confirmed that a low angle boundary is observed in the warm rolled sheet and a high angle boundary is observed in the cold rolled sheet. It is clearly found that a PFZ is restrained at the low angle boundary, whereas a PFZ is formed distinctly at the high angle boundary. Other grain boundary areas of the both sheets showed the same characteristic on the PFZ formation. In the case of narrow PFZ formation, the difference of electrochemical property between the grain boundary area and the grain interior tends to reduce, which would prevent a partial anodic reaction and lead to the improvement of resistance to SCC. ${ }^{14,15)}$

\section{Conclusions}

The mechanical properties on the warm rolled sheets of AA7475 based aluminum alloy containing zirconium with fine subgrain structure were investigated comparing with conventional AA7475 aluminum alloy sheets produced by cold rolling. The following points can be made:

(1) The warm rolled sheets show the high r-value of 3.5 in the orientation of $45^{\circ}$ to rolling direction due to well developed $\beta$-fiber components, especially with the strong $\{011\}\langle 211\rangle$ Brass component after solution heat treatment.

(2) The average r-value of the warm rolled sheets is higher than that of the cold rolled sheets, so that the warm rolled 
sheets have better deep drawing properties in O-temper.

(3) PFZ is hardly formed along the low angle boundaries of the warm rolled sheets in T6 condition, which would lead to the improvement of resistance to SCC because of the uniformity of electrochemical property between the grain boundary area and the grain interior.

(4) The fatigue strength of the warm rolled sheets in the orientation of $0^{\circ}$ to rolling direction is about $10 \%$ higher than that of the cold rolled sheets.

\section{Acknowledgements}

This work was supported in part by a research fund of the Super Aluminum Project provided by the Japan Research and Development Center for Metals (JRCM) in the New Energy and Industrial Technology Development Organization (NEDO). The authors thank JRCM and NEDO for the permission of publication of this report.

The authors also acknowledge Professor Z. Horita, Kyushu University in Japan, for the measurements of the grain boundary misorientations by Kikuchi lines of TEM images.

\section{REFERENCES}

1) E. O. Hall: Proc. Phys. Soc. 64 (1951) 747.

2) N. J. Petch: Iron Steel Inst. 25 (1953) 197.

3) The Society of Japan Aerospace Companies: Investigation for the promotion of aero parts and materials industries No. 807, (1994).

4) T. Minoda, H. Tanaka, K. Shibue and H. Yoshida: J. Japan Inst. Light Metals 51 (2001) 651.

5) H. Tanaka, T. Minoda, H. Esaki, K. Shibue and H. Yoshida: J. Japan Inst. Light Metals 52 (2002) 29.

6) The Society of Japan Aerospace Companies: Investigation for the promotion of aero parts and materials industries No. 904, (1995).

7) H. Tanaka, T. Minoda, H. Esaki, K. Shibue and H. Yoshida: Proceedings of 8th International Conference ICAA8, Cambridge, UK, (2002), 499.

8) H. J. Bunge: Texture analysis in materials science, (Butterworths, 1982).

9) S. Hirano and H. Yoshida: Sumitomo Light Metal Technical Reports 38 (1997) 95.

10) K. Takeuchi: J. Light Metal Welding and Construction 4 (1966) 184.

11) H. Inoue and N. Inakazu: J. Japan Inst. Light Metals 44 (1994) 97.

12) G. I. Taylor: J. Inst. Metals 62 (1938) 307.

13) T. Minoda and H. Yoshida: Metall. Mater. Trans. A 33A (2002) 2891.

14) E. N. Pough and W. R. D. Jones: Metallurgia 63 (1961) 3.

15) Y. Murakami: J. Japan Inst. Light Metals 31 (1981) 748. 